\title{
Analysis of Utilisation States and Reliability Parameters of Process-Line Configuration for Low-Quality Rock Deposits
}

\author{
Przemysław Bodziony ${ }^{1 *}$, Michał Patyk ${ }^{1}$ \\ 1 AGH University of Science and Technology, Faculty of Civil Engineering and Resource Management, Al. \\ Mickiewicza 30, PL-30-059 Cracow, Poland. \\ * Corresponding author's e-mail: przembo@agh.edu.pl
}

\begin{abstract}
The production performance of mining and also construction equipment (like haul trucks, excavators, loaders, crushing and screening equipment) depends on its availability and utilisation states. Thus, it is necessary to determine the mean availability and structure utilisation of machinery systems with the aim to improve the same. At the same time, a detailed analysis of machinery operation data can result in a more effective management of mining plant operations and the mining process itself. Determination of operational state indices and their individual components allows to start preventive actions, resulting in the improvement of the organisation of work of the entire mine machinery system. Moreover, the future technical state of machines operated in surface mining is closely related to the current state and depends also on the events that have occurred in the extraction system. The analysis of dependability parameters can have a significant impact on decision-making, related both to the processes of use and maintenance, and, primarily, to all main operational processes of the mine. Different mines follow different terms and maintain different information. The only common information in most of them concerns the availability and utilisation of mining and construction equipment, which might be useful. There is a need to develop proper feedback and to define terms, factors and indices related to mining equipment. Below follows an analysis of selected operational parameters and the mean availability in the process of using the mining and construction equipment. This type of analyses help determine the operational potential of every element in the engineering system, understood as the ability to perform work processes. The analyses also illustrate how the reliability parameters change with the durability of the operated machinery. This makes it possible to identify the machines with the highest and lowest damage rates and such analyses can form the basis for the creation of optimised machine systems.
\end{abstract}

Keywords: surface mining, construction industry, mining equipment, construction equipment, failure intensity, utilisation, reliability parameters.

\section{INTRODUCTION}

Rational solutions for mining and construction equipment based on the use of haul trucks, excavators, wheel loaders and crunchers should result from a thorough analysis of technical and economic issues - both cost- and operation-related - which can have a crucial impact on the cost of extracting minerals. Moreover, mining and construction equipment should be selected in consideration of all the vital parameters in specific operating conditions and even the operator's preferences. This selection should consider hitherto disregarded criteria, such as mean availability and structure utilisation of machinery systems with the aim to improve the same [1]. Recent examples of studies are $[2 \div 6]$. Considering the above issues, the following paper is an attempt at developing new and universal criteria as well as a method of evaluation and selection of means of mining equipment for mineral resource open-pit mines. This is particularly important in case of preliminary crushers, which typically occur as single units, forming a serial and parrarel reliability structure with other machines. 
The production performance and profitability of rock mines and construction industry is closely related to the elements of the operation process of the entire machinery system (haul trucks, wheel loaders and processing equipment). A detailed analysis of fault data and other operational parameters of each element of the machinery system can contribute to more effective management of the mining plant operation and the extraction process. Furthermore, the future technical condition of surface mining machines is closely connected with the current state of affairs and depends on the events that have already taken place in the operation system. The analysis of the operational statuses and their individual elements makes it possible to undertake preventive measures, leading to the improved operation of the entire machinery system in mining. It is recommended that information on the operation of machines in surface mining be standardised. This is particularly important in case of preliminary crushers, which typically occur as single units, forming a serial and parrarel reliability structure with other machines. Reliability assessments of repairable mining machines have been reported in some papers $[3,7,8]$. Esmaeili and Nabizadeh $[9,10]$ discussed loading and hauling, which their failure rate and profitability of mines. Allahkarami and Kumar $[3,11]$ analyzed the reliability of haul trucks and failure rate consequences. Therefore, reliability analysis is required to identify the bottlenecks in the machine system and to find the components or subsystems with low reliability for a given designed performance $[12,13]$.

The proposed methodology, illustrated with an example of the selected mine, is universal and can be applied in other mining plants. This paper attempts to analyse the most important operational parameters of the individual elements of the machinery system constituting the engineering system of a rock mine - loaders (wheel loaders), transport machines (haul trucks) and processing machines (jaw crushers). Also it can be used for analysing of machine systems in construction industry.

\section{PROCESS-LINE CONFIGURATION FOR LOW-QUALITY RAW MATERIAL}

As a result of karstic formations, $20 \%$ of the studied limestone seam comprises ungraded material (waste stone) which is unfit for use further in the process. In our study, we used the term seam quality 80 , meaning that intermediate product comprises $80 \%$ of the seam, and assuming that the rock extracted from the bed should be preliminarily crushed to remove the karst fraction, with a particular size distribution of $0-40 \mathrm{~mm}$, from the final material. The fraction that is fit for use further in the process (intermediate product) has a particular size distribution of more than $40 \mathrm{~mm}$. Three possible process-line configurations were proposed to select the best alternative for the seam conditions under study. In this mining system, the extracted rock a wheel loaders was used to load haul trucks; rigid-frame haul trucks with a capacity of $55 \mathrm{Mg}$ were used to transport the extracted rock to the waste rock dump for preliminary crushing of ungraded material, and to transport intermediate product to the processing plant. The location of preliminary crusher is different for each of the mining systems compared (Fig. 1) [14].

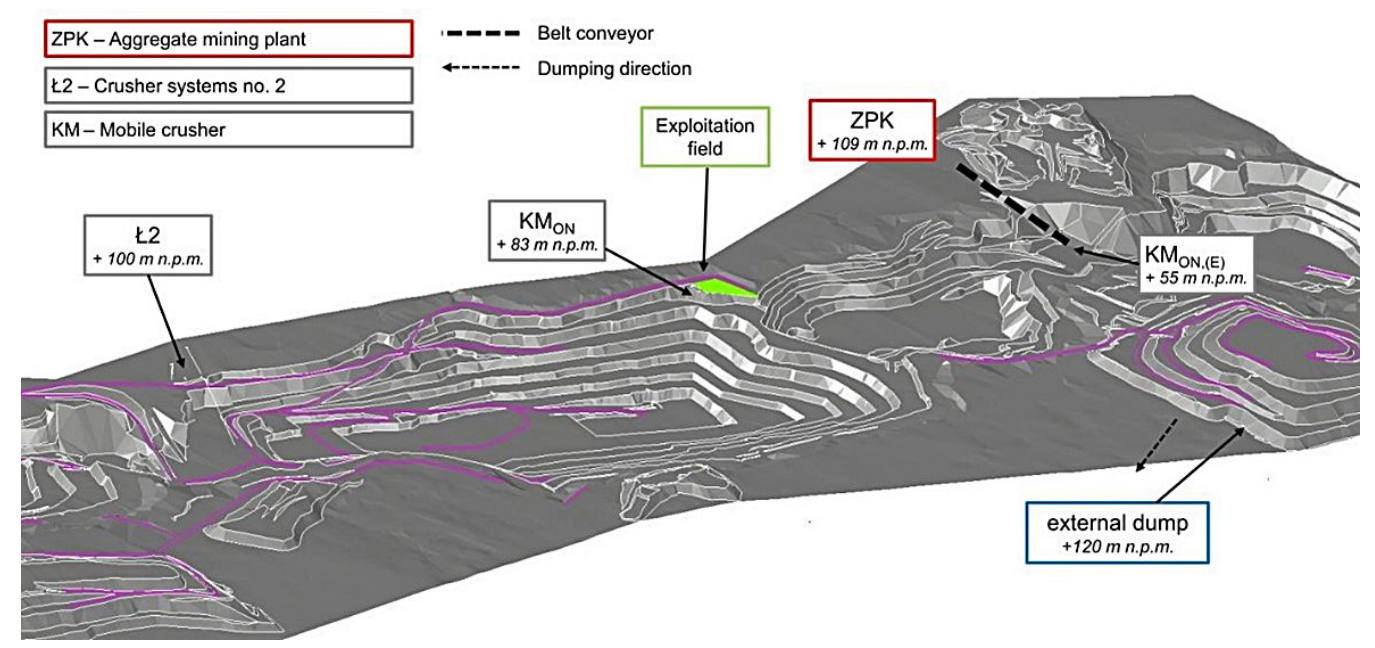

Fig. 1. Preliminary crushing locations in the analysed mine [14] 


\section{AN ANALYSIS OF FAILURE INTENSITY AND THE RELIABILITY FUNCTIONS OF THE INDIVIDUAL ELEMENTS OF THE MACHINERY SYSTEM}

Failure intensity can be estimated on the basis of statistical analyses as a parameter which describes the number of cases (failure density) of individual machines being disengaged from the operation system as a result of a failure. This parameter makes it possible to determine the average number of service requests to the restoration system for a given machine, while disregarding the time to restoration [15]. As a result, several studies have been performed to study the analyzing failure intensity of mining machines $[12$, $16,17]$ The failure intensity parameter was determined as a mean of the number of failures for each analysed machine during the total analysed period of time according to dependence (1). The failure intensity was determined as the mean value of exclusions for the analysed mining equipment population, falling to the entire range of analysed operation time (14.000 hours of operation) acc. to relationship (1) $[12,17 \div 21]$. This parameter's value is expressed as [failure/hours of operation].

$$
\lambda(t)=\frac{n_{i}(\Delta t)}{N(0) \cdot \Delta t}
$$

where: $n_{i}(\Delta)$ - the number of registered damages in the $i$-th range of the analysed duty [damages], $N(0)$ - the number of specific type of machines in the analysed population [units], $\Delta t$ - the total length of the range of the analysed duty (engine hours).

Malfunctioning machines were not replaced with operational ones during the analysis - no cold reserve. In order to determine failure intensity, separate analyses were conducted for each machine type. Also, cumulative failure intensity was analysed for the individual groups and the entire machinery system. Group $L 1$ included four wheel loaders with a service live of 0 to 14,000 hours of operation (Fig. 2). Group W2 included five haul trucks with a service live of 0 to 13,000 hours of operation (Fig. 3). Item N3 was a single technical item - a jaw crusher.

The distribution of failure intensity was determined for all machines based on service requests submitted to the restoration system. These requests included serious failures as well as minor defects indicated and detected by the telemetry system or the operators. They were treated equally due to the resulting necessity to disengage a given item from engineering operations. All maintenance requests were registered in an especially prepared spreadsheet comprising a precise time of the

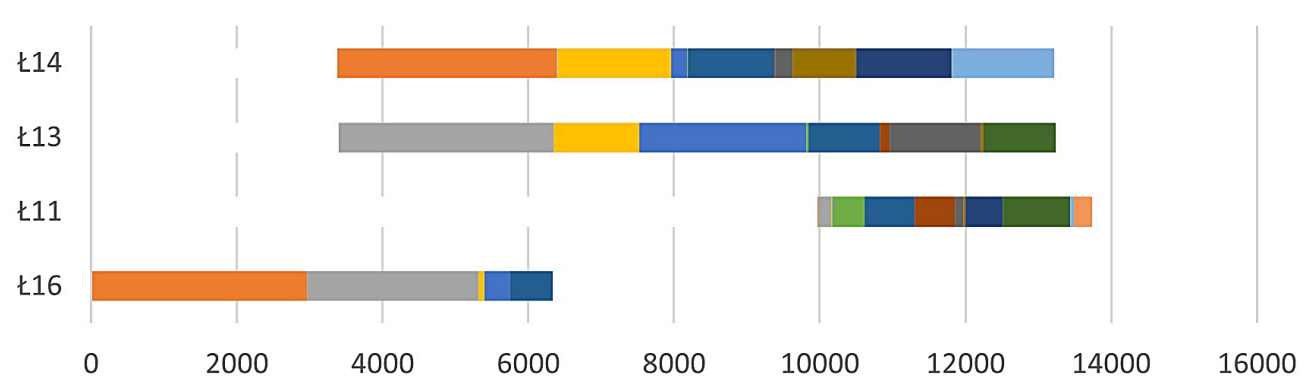

Fig. 2. Detailed histogram of failure intensity in the $L 1$ loader group

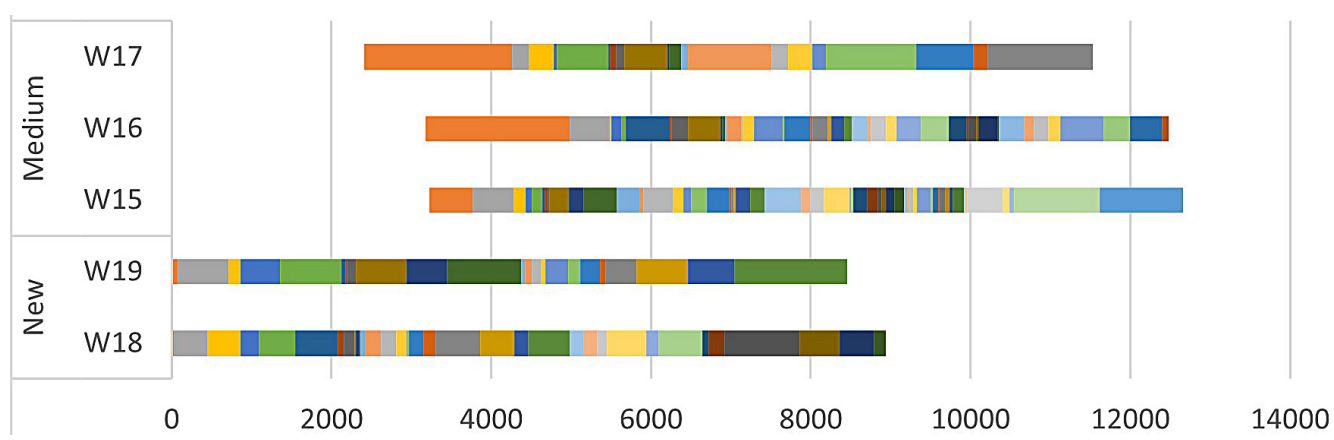

Fig. 3. Detailed histogram of failure intensity in the $W 2$ haul truck group 
failure occurrence (request), for a specific value of the operation time (in hours of operation), for each type of machine on an individual basis. The total range of cumulative failure intensity for two comparable sets of machine resources ( $L 1$ and W2) was assumed for the durability of 0 to 14,000 hours of operation (Fig. 4). The total range for the analysis of (jaw crusher) N3 was 12,000 hours of operation. A chart of the failure intensity function $\lambda(t)$ was drawn up for cumulative failure intensity, and the density of the Weibull distribution was assumed according to $[12,22,23]$. In the preparation of the Weibull distribution, it was assumed that the probability of an event in a short period of time $\Delta t$ was approximately equal to $\lambda i$ $\Delta t$, i.e. the average number of events per unit of time changes with time and depends on the observation period [24]. For the purpose of failure intensity and reliability functions analyses, it was assumed that the observation would continue until a specific number of items fail. In such a case the number of failures (fraction) was determined and the time until failure was a random variable. The analysis was conducted until complete data were obtained either for all events or for a pre-specified number of events. All the analysed machines were in a similar technical condition (they were fully operational) and each item in the sample was used under exactly the same conditions [25].

The history of the failure intensity parameter for the $L 1$ group as regards cumulative intensity illustrates the initial period of operation (0-10,000 hours of operation), with increased failure intensity which decreases with time. This effect can be explained by various manufacturing or installation defects, etc. constituting the main cause of failure in the initial period of operation. In the next period (more than 12,000 hours of operation) of operation, failure intensity is much lower, due to both the defects being eliminated beforehand and the appropriate quality of operation. A similar course of operation can be observed in the case of $W 2$ haul trucks (Figure 5).

The history of the failure intensity parameter for the $W 2$ haul trucks as regards cumulative intensity illustrates the initial period of haul truck operation $(0-7,500$ hours of operation), with increased failure intensity which decreases with

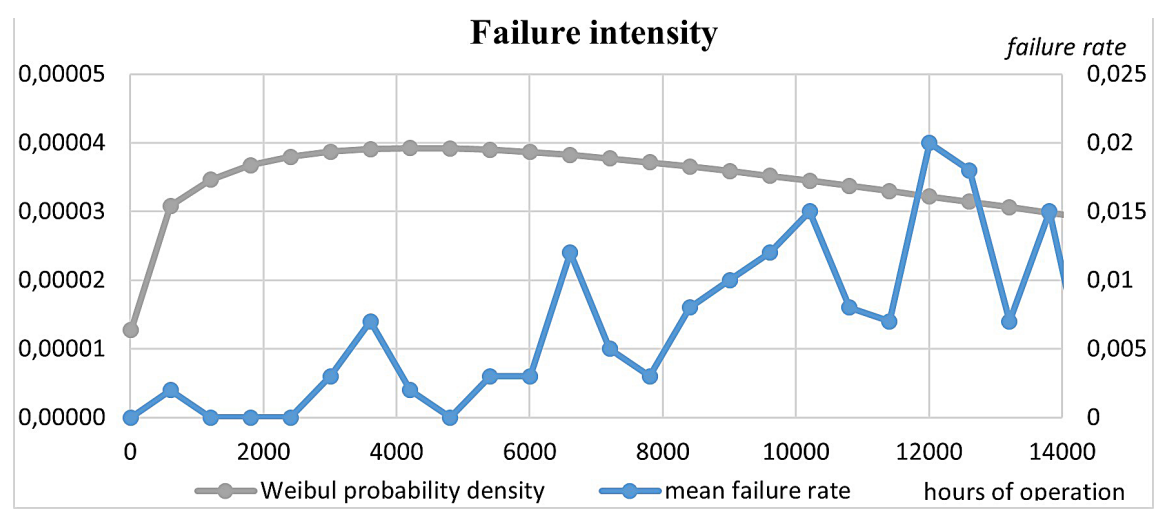

Fig. 4. The failure intensity parameter for $L 1$ loaders, for a total observation period of 14,000 hours of operation

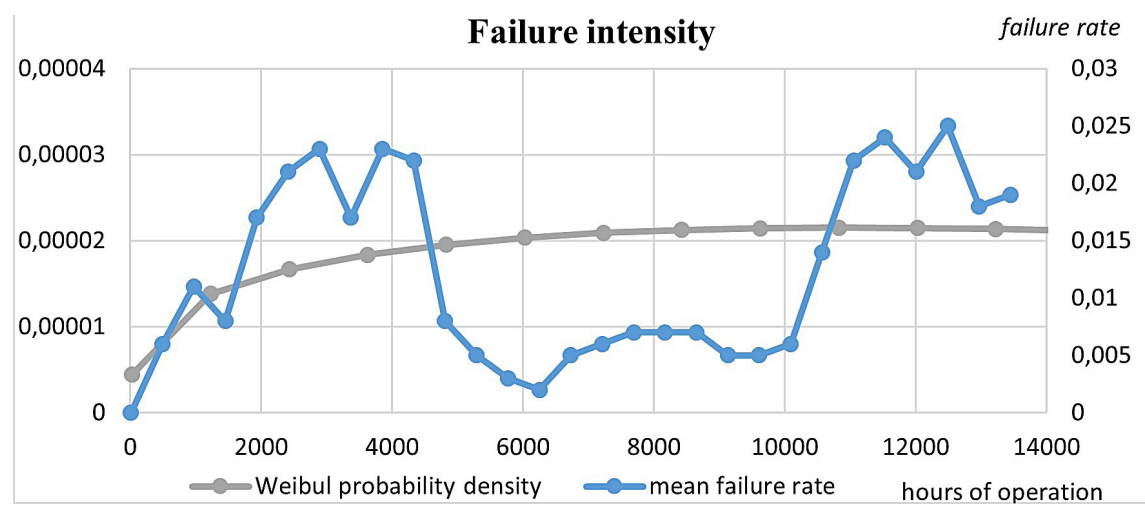

Fig. 5. The failure intensity parameter for $W 2$ haul trucks, for the total observation period of 14,000 hours of operation 


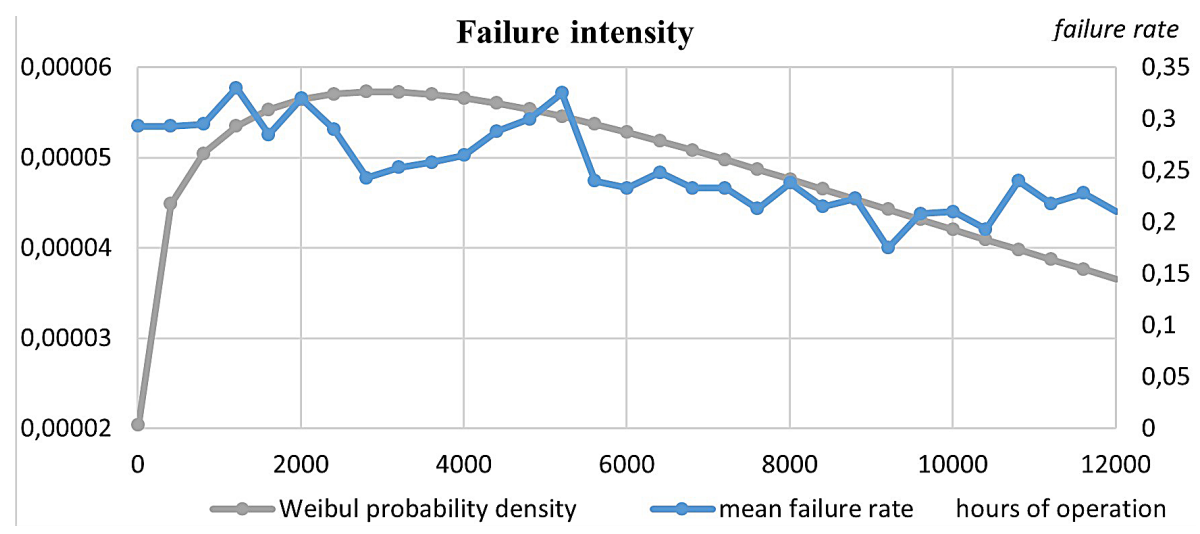

Fig. 6. The failure intensity parameter for $N 3$ jaw crusher, for the total observation period of 12,000 hours of operation

time. In the next period $(8,000-14,000$ hours of operation) of vehicle operation, the observed failure intensity was much lower and remained roughly constant (Figure 6).

The history of the failure intensity parameter for the jaw crusher (item N3) illustrates the initial period of operation ( $0-1,500$ hours of operation) characterised by increased failure intensity. In the next period (4,000-12,000 hours of operation) of its operation, the observed failure intensity was much lower and stable.

After analysing the failure intensity parameters for the individual elements of the machinery system it was concluded that failure density was the highest in the case of the jaw crusher (item N3). This was attributed to the conditions and nature of its use. This finding was significant especially given the fact that it is a single technical item and its disengagement paralyses the entire machinery system of the mine. A slightly lower failure intensity was observed for wheel loaders, while the lowest was recorded for haul trucks, despite the latter including the largest number of items.
Next, based on the aforementioned data, empirical reliability function analyses were conducted for the individual elements of the machinery system ( $L 1, W 2$ and N3). This indicator describes the probability of the item remaining in full working order as a function of its operating time. The probability of correct operation was calculated for the operating time range starting at the initial point (operating time of 0 hours of operation) and ending at $14,000(L 1, W 2)$ or 12,000 (N3) hours of operation (Figure 7-9). For reliability analysis, the manner in which restoration occurs (whether it is through replacement of a failed element with a new one or repair of such an element) is irrelevant. Furthermore, time to restoration, which comprises, among others, time needed to diagnose the failure, time needed to assemble the materials and spare parts for repairs and time needed to perform the repairs, is also treated as a whole (Zótkowski, Cmable 2005) [26]. Reliability until failure (in hours of operation) was assumed as the random variable determining the failure intensity of a machine with the following reliability function $[18 \div 20]$ :

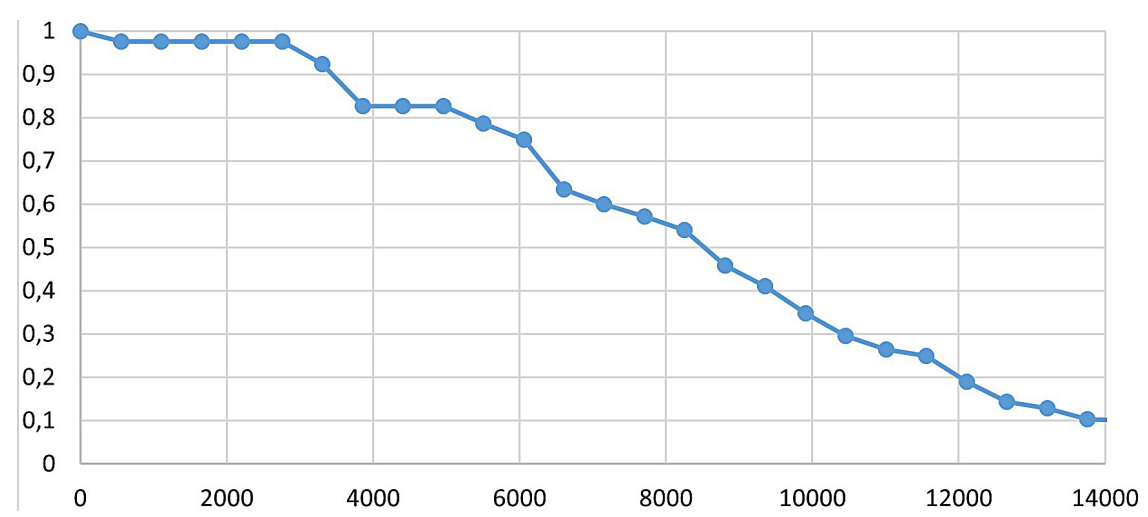

Fig. 7. Empirical cumulative reliability function in the $L 1$ wheel loader group 


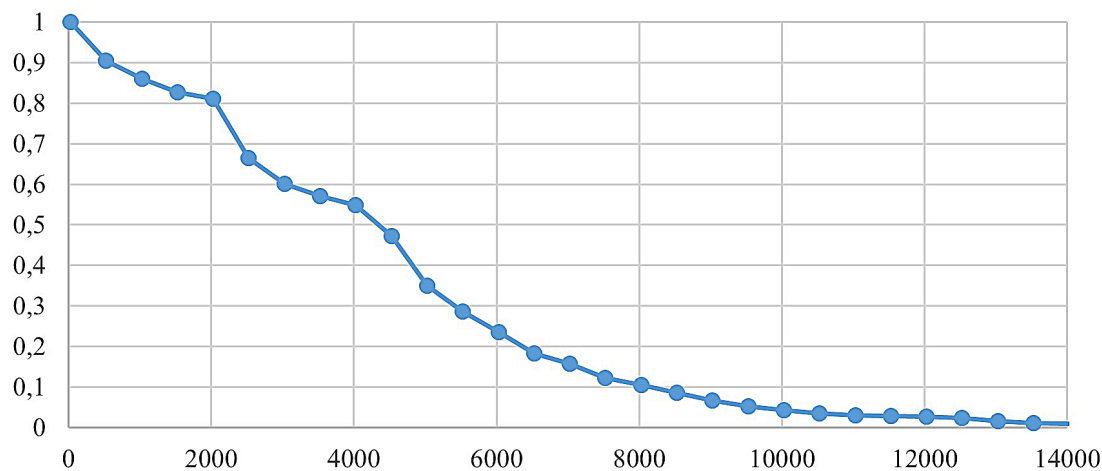

Fig. 8. Empirical cumulative reliability function in the $W 2$ haul trucks group

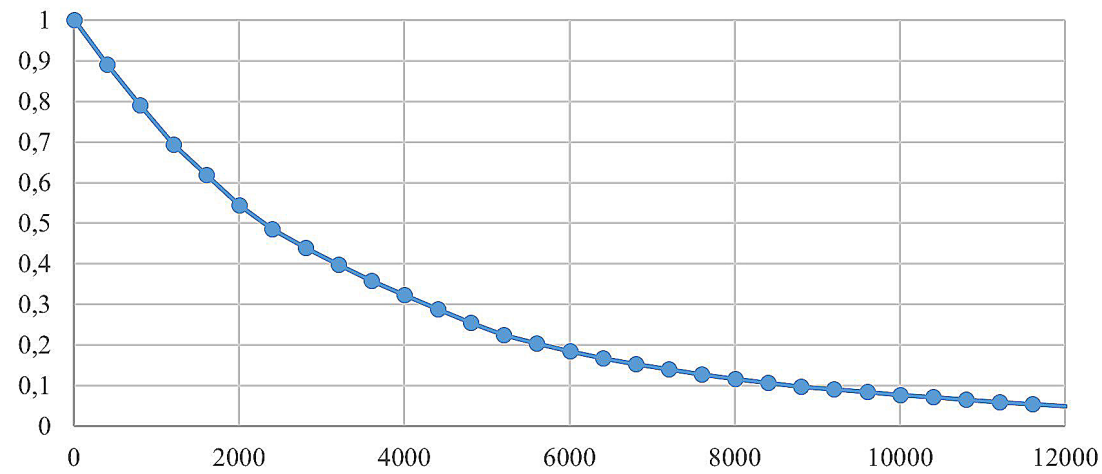

Fig. 9. Empirical cumulative reliability function for the $N 3$ item (jaw cruscher)

$$
R(t)=\frac{N(0)-n(t)}{N(0)}
$$

where: $R(t)$ - probability of correct machine operation in the operating time range of 0 to $\mathrm{t}$ [hours of operation], $N(0)$ - total number of machines comprising the analyzed group, $n(t)$ - number of machine failures during the defined period of operation (14,000 hours of operation).

The analyses of the histories of the reliability functions for individual elements of the machinery system for the assumed values show that, for the durability of the $N 3$ item (jaw crusher), amounting to about 2,000 hours of operation, the probability of failure/malfunction is $55 \%$. The same probability of failure for $L 1$ items (wheel loaders) is reached at 4,000 hours of operation, and for $W 2$ items (haul trucks) at more than 8,000 hours of operation. What is worth highlighting for the $W 2$ group is that a reliability of $97 \%$ is reached as early as at 3,000 hours of operation. This stems from the history of the empirical reliability function.

Reliability function provides a good comparison of durability of the utilised technical items machinery and equipment - and, at the same time, gives grounds for drawing conclusions concerning the prevalence of a type of failure process and probability of correct operation at a given time and under specific conditions. The analysis of determining the reliability function of mining machinery equipment, as presented above, included failures resulting from imperfections in their manufacture or assembly. Furthermore, it encompassed failures resulting from operation and operators' errors, and those associated with the impact of the environment. Such analyses make it possible to forecast the reliability function, which can be implemented as a sequence of basic functions of the generalized polynomial of a function, which describe the reliability function in most common cases.

\section{CONCLUSION}

The unsatisfactory condition of use and restoration of mining and construction machinery usually stems from the lack of real durability and reliability characteristics of the individual types of machines operated in specific conditions. The conducted analyses indicated a strong correlation between empirical reliability parameters and 
theoretical curves, especially in the case of the failure intensity function. The analyses also illustrate how the reliability parameters change with the durability of the operated machinery.

In all analysed machine cases, failure intensity increases with operating time, and then stabilises. It was shown that there are considerable reliability differences between individual items which form the machinery system. This is especially true in case of preliminary crusher, which demonstrates the highest failure intensity and, as a single technical item connected in series to other elements (machines), may lead to a downtime of the entire machinery system.

Such analyses help determine the operational potential of every element in the engineering system (mining and also construction industry), understood as the ability to perform work processes. In addition, they make it possible to determine items with the highest and lowest failure rates. Owing to the above, similar operating characteristics can form the basis for the creation of optimised systems of operation, e.g. the manner and frequency of carrying out planned inspections.

\section{Acknowledgments}

This research was funded by AGH University of Science and Technology, Faculty of Civil Engineering and Resource Management; subsidy number: 16.16.100.215.

\section{REFERENCES}

1. Bodziony P., Patyk M., Kasztelewicz Z. Analysis of operating states of haul trucks used in surface mining. Journal of KONES: Powertrain and Transport. 2018;25(2):53-58.

2. Sinha R.S., Mukhopadhyay A.K. Failure rate analysis of jaw crusher using Weibull model. Proceedings of the Institution of Mechanical Engineers, Part E: Journal of Process Mechanical Engineering. 2017;231(4):760-772. https://doi. org/10.1177\%2F0954408916636922

3. Allahkarami Z., Sayadi A.R., Ghodrati B. Identifying the mixed effects of unobserved and observed risk factors on the reliability of mining hauling system. International Journal of Systems Assurance Engineering and Management. 2021;12(2):281289. https://doi.org/10.1007/s13198-021-01073-3

4. Hall R.A., Daneshmend L.K. Reliability modelling of surface mining equipment: Data gathering and analysis methodologies. International Journal of Surface Mining, Reclamation and Environment. 2003;17(3):139155. https://doi.org/10.1076/ijsm.17.3.139.14773

5. Hall R.A., Daneshmend L.K., Lipsett M.G., Wong J. Reliability analysis as a tool for surface mining equipment evaluation and selection. CIM Bulletin. 2000;93(1044):78-82.

6. Singh A., Rai P., Sharma N., Pandey J. Failure Analysis and Performance Improvement Using Surface Miner on Field Breakdown Data: A case study. Industrial Engineering Journal. 2019;12(9). https://doi.org/10.26488/iej.12.9.1198

7. Morad A.M., Pourgol-Mohammad M., Sattarvand J. Application of reliability-centered maintenance for productivity improvement of open pit mining equipment: Case study of Sungun Copper Mine. Journal of Central South University. 2014;21(6):2372-2382. https://doi.org/10.1007/ s11771-014-2190-2

8. Stuchlý V., Poprocký R., Kaczmarek M. Reliability evaluation as a means of increasing the efficiency of equipment maintenance. Adv. Sci. Technol. Res. J. 2016;10(32):40-46. https://doi. org/10.12913/22998624/65109

9. Esmaeili M., Bazzazi A.A., Borna S. Reliability analysis of a fleet of loaders in sangan iron mine. Archives of Mining Sciences. 2011;56(4):629-640.

10. Nabizadeh M.A., Jalali S.M.E., Soltani A., Khademian A., Barabady J. Reliability and Maintainability Analysis of Material Handling Machinery in Golegohar Mine No. 1. In: Proc. of 4th International Conference on System Reliability and Safety, ICSRS, Rome, Italy 2019, 224-229. https://doi. org/10.1109/ICSRS48664.2019.8987634

11. Kumar U., Klefsjö B., Granholm S. Reliability investigation for a fleet of load haul dump machines in a Swedish mine. Reliability Engineering and System Safety. 1989;26(4):341-361. https://doi. org/10.1016/0951-8320(89)90004-5

12. Barabady J., Kumar U. Reliability analysis of mining equipment: A case study of a crushing plant at Jajarm Bauxite Mine in Iran. Reliability Engineering and System Safety. 2008;93(4):647-653. https://doi.org/10.1016/j.ress.2007.10.006

13. Sinha R.S., Mukhopadhyay A.K. Reliability centered maintenance of cone crusher: a case study. International Journal of Systems Assurance Engineering and Management. 2015;6(1):32-35. https:// doi.org/10.1007/s13198-014-0240-7

14. Bodziony P., Patyk M., Kasztelewicz Z. Multi-criteria decision making for the choice equipment in mining with application of AHP method. New Trends in Production Engineering. 2019;2:404-415.

15. Bentley J.P. Introduction to reliability and Quality engineering. Addison-Wesley; 1999. 
16. Hall R.A., Daneshmend L.K. Evaluation of reliability and availability of surface mining equipment. Journal of Mines, Metals and Fuels. 2002;50(10-11):395-400.

17. Gbadam E., Awuah-Offei K., Frimpong S. Investigation into mine equipment subsystem availability and reliability data modeling using discrete event simulation. In: Proc. of 37th International Symposium - Application of Computers and Operations Research in the Mineral Industry, APCOM, United States 2015, 544-552.

18. Hebda M. Eksploatacja samochodów. Instytut Technologii Eksploatacji - PIB; 2005.

19. Hebda M., Janicki D. Trwałość i niezawodność samochodów w eksploatacji. Wydawnictwo Komunikacji i Łączności WKł; 1977.

20. Migdalski J. Inżynieria niezawodności. ZETOM; 1992.

21. Liu T., Zhang Z., Pan H. Failure mode effect and criticality analysis of the underground mining environment detector test system. Internation- al Journal of Applied Environmental Sciences. 2013;8(19):2441-2448.

22. Yiqiang W., Yazhou J., Weiwei J. Early failure analysis of machining centers: a case study. Reliability Engineering and System Safety. 2001;72.

23. Bebbington M., Lai C.D., Zitikis R. A flexible Weibull extension. Reliability Engineering and System Safety. 2007;92(6):719-726. https://doi. org/10.1016/j.ress.2006.03.004

24. ReliaSoft Corporation. Life Data Analysis Reference. Weibull++ 7. Reliasoft Publishing. Tucson AZ, USA 2008.

25. Bodziony P., Kudelski R., Patyk M., Kasztelewicz Z. Use of Artificial Neural Networks for the Estimated Prediction of Haul Trucks Operating States. In: Proc. of 14th International Scientific Conference: Computer Aided Engineering, Poland 2019.

26. Żółtowski B., Cempel C. Inżynieria diagnostyki maszyn. ITeE; 2005. 